\title{
PENERAPAN TEKNOLOGI TEPAT GUNA SEBAGAI PENINGKATAN KAPASITAS MESIN PENGAYAK PASIR TIPE ROTARY DAN USAHA DUSUN TANGGALAN, KABUPATEN KARANGANYAR
}

\section{Catur Harsito ${ }^{1}$, Aditya Muhammad Nur ${ }^{1}$, Ari Prasetyo', Teguh Triyono ${ }^{2}$, Rendy Adhi Rachmanto², Budi Santoso ${ }^{2}$}

${ }^{1}$ Teknik Mesin Vokasi, Universitas Sebelas Maret, Jl. Ir. Sutami No.36A, Surakarta, 57126, Indonesia.

2Teknik Mesik Fakultas Teknik, Universitas Sebelas Maret, Jl. Ir. Sutami No.36A, Surakarta, 57126, Indonesia.

Email: catur_harsito@staff.uns.ac.id

\begin{abstract}
ABSTRAK
Pembangunan infrasturktur yang semakin meningkat pesat berakibat dengan meningkatnya kebutuhan bahan pasir. Disisilain, pasir yang tersedia dipasaran masih mengandung banyak komponen lain seperti batu kerikil. Ukuran pasir yang baik menurut Standar Nasional Indonesia (SNI - 03-2472002) yaitu pasir alami atau pasir buatan hasil industri pemecah batu dengan ukuran butiran terbesar adalah $5 \mathrm{~mm}$. Pada lain pihak, infrastruktur Dusun Tanggalan yang kurang, dan penghasilan Dusun yang kecil menjadikan pemerataan ekonomi daerah yang tidak merata. Pemuda dan kepala Dusun Tanggalan melihat adanya potensi untuk meningkatkan penghasilan Dusun dengan membuat usaha pengayakan dan penyedia pasir bangunan dengan kualitas bagus. Proses pengayakan manual membutuhkan waktu lebih lama, sehingga berdampak dalam proses pembangunan serta dari segi ekonomi pada biaya pembanguna yang lama. Maka perlu adanya mesin pengayak otomatis tipe rotari yang memiliki fungsi untuk memisahkan butiran pasir halus atau sesuai dengan kriteria yang diminta konsumen dengan batu kerikil. Mesin pengayak tipe rotari dengan kapasitas $10 \mathrm{~m}^{3} / \mathrm{jam}$, sehingga diharapkan dapat memenuhi permintaan dan juga membantu dalam proses percepatan pembangunan. Selain itu, dengan alat ini dapat terbentuk usaha Dusun sebagai peningkatan pendapatan Dusun.
\end{abstract}

Kata kunci: Bisnis, Pengayak Pasir, Peningkatan, Rotari, Standar Nasional

\section{ABSTRACT}

The increasing of infrastructure development causing in increased demand for sand material. On the other hand, the sand still contains many other components such as gravel. The size of good sand according to the Indonesian National Standard (SNI 03-247-2002) is natural or artificial sand produced by the stone crusher industry with the largest grain size of $5 \mathrm{~mm}$. On the other hand, the lack of infrastructure of the 
Tanggalan vilage and the small income of the village has resulted in an uneven distribution of the regional economy. Youths and heads of the Tanggalan village see the potential to increase the village's income by making sieving businesses and providing good quality building sand. The manual sieving process takes longer, so it has an impact on the development process as well as from an economic point of view on the long construction costs. So, it is necessary to have a rotary type automatic sieving machine that has a function to separate fine sand grains or according to the criteria requested by consumers with gravel. Rotary type sieving machine with a capacity of 10 $\mathrm{m}^{3} /$ hour, so it is expected to meet the demand and accelerating development process. In addition, with this tool, hamlet businesses can be formed to increase hamlet income.

Key words: Business, Enhancement, National Standard, Rotary, Sand Sieve.

\section{PENDAHULUAN}

Ilmu pengetahuan dan teknologi yang semakin berkembang menghasilkan pola pikir manusia yang berubah dalam melakukan proses produksi suatu bahan dengan mempertimbangkan efektifitas dan kualitas serta biaya produksi (Perdana \& Rusdiyantoro, 2013; Siahaan, 2018). Saat ini pembangunan infrastruktur semakin meningkat dengan adanya perkembangan bisnis property seperti villa, hotel, cottage dan juga apartemen (Aditya et al., 2018). Perkembangan ini memicu terjadinya peningkatan perkembangan didaerah Dusun Tanggalan, Sringin, Jumantono, Karanganyar. Proses pembangunan yang semakin meningkat dan meluas menjadikan permintaan akan bahan material ikut meningkat, salah satunya pasir. Pasir merupakan material utama dan penting dalam bidang konstruksi bangunan, baik untuk bangunan rumah tempat tinggal, tempat ibadah, perkantoran, maupun gedung-gedung sarana pendidikan serta bangunanbangunan lainnya (Fattah, 2017; Tani, n.d.). Bangunan yang baik merupakan bangunan yang dibangun dengan menggunakan bahan material yang baik. Pasir yang baik adalah pasir dengan ukuran butiran yang seragam. Ukuran pasir yang baik menurut Standar Nasional Indonesia (SNI - 03247-2002) yaitu pasir alami atau pasir buatan hasil industri pemecah batu dengan ukuran butiran terbesar adalah $5 \mathrm{~mm}$ (Badan Standardisasi Nasional, 2002). Namun, pasir yang beredar dipasaran merupakan pasir yang masih memiliki ukuran tidak seragam bahkan hampir sebagian besar terdapat bahan pengotor lainnya seperti kerikil dan batu. Pasir yang tersedia harus dipisahkan dengan bahan lainnya untuk memenuhi kriteria sebagai bahan konstruksi bangunan.

Pada sebagian besar daerah, untuk mendapatkan pasir dengan ukuran yang seragam maka dilakukan proses pengayakan. Proses pengayakan yang dilakukan secara manual, sehingga membutuhkan banyak waktu dan tenaga manusia juga waktu yang lama. Penggunaan tenaga manusia pada proses pengayakan berakibat juga pada waktu pembangunan yang semakin lama. Sehingga, berdampak pada dana pembangunan yang dikeluarkan 
akan membengkak pada biaya ongkos tenaga kerja. Sebagian besar daerah pedesaan, proses pengayakan akan sangat mempengaruhi dana yang dibutuhkan untuk melakukan pembangunan. Di daerah Dusun Tanggalan, Sringin, Jumantono, Karanganyar, proses pengayakan masih menggunakan pengayakan manual, sehingga proses pembangunan menjadi sangat lama dan membutuhkan biaya yang tinggi.

Sebagai upaya untuk meminimilkan penggunaan tenaga manusia pada proses pengayakan, maka perlu adanya mesin pengayak pasir tipe rotari. Selain penggunaan tenaga manusia yang sedikit juga waktu proses pengayakan akan lebih cepat. Namun, pada mesin ini masih membutuhkan tenaga manusia sebagai operator dan penumpah pasir. Penerapan teknologi tepat guna pada masyarakat akan meningkatkan produktifitas proses yang dilakukan (Aditya et al., 2018; Arifin et al., 2020; Prasetyo \& Harsito, 2019; Sateria et al., 2019; Tjahjana et al., 2019). Disamping itu, dengan menggunakan mesin pangayak pasir tipe rotary ini memiliki keuntungan yaitu waktu yang dibutuhkan lebih pendek, hasil produksi yang lebih tinggi dibandingkan dengan system manual. Salain itu, mesin ini juga memiliki keunggulan yaitu dengan adanya corong pemisah antara pasir dan kerikil/batu. Corong pemisah ini juga terletak pada sisi yang berbeda sehingga memudahkan untuk memisahkannya.

Pemerataan ekonomi Dusun yang tidak merata merupakan dampak dari pembangunan infrastruktur yang kurang serta penghasilan daerah yang kecil. Penyediaan jasa pengayakan serta penyedia bahan bangunan dilihat sebagai potensi peningkatan penghasilan Dusun oleh kepala Dusun dan pemuda Tanggalan. Lokasi mitra yang tidak jauh dari pusat kota ditunjukkan pada Gambar 1 hanya sekitar 15 menit perjalanan darat menjadikan lokasi ini memiliki potensi untuk melakukan usaha pengayakan pasir dengan kualitas baik. Dusun Tanggalan yang dipimpin oleh seorang kepala Dusun Bp. Wiyono melihat adanya permasalahan ini. Disisilain, Dusun Tanggalan memiliki penghasilan daerah relative rendah dan tidak menetap. Solusi dari permasalahan ini perlu adanya penerapan Teknologi Tepat Guna untuk meningkatkan pembangunan dengan adanya mesin pengayak tipe rotari dan juga menjadi usaha Dusun.

\section{METODE}

Berdasarakan permasalahan yang ada dan solusi yang ditawarkan, maka pelaksanaan kegiatan pembuatan mesin pengayak pasir tipe rotari ini dijabarkan sebagai berikut:

\section{Pengumpulan referensi dan diskusi:}

Tim pelaksana, tim perancang mesin dan mitra melakukan diskusi berdasarkan permasalahan yang ada dan juga tim perancangan malakukan pengumpulan referensi alat dan kebutuhan. Selain itu mengumpulkan informasi sebanyak mungkin yang ada di lapangan tentang kondisi kebutuhan spesifikasi yang harus dipenuhi oleh produk. 


\section{Merancang/mendesain alat:}

Tim pelaksana melakukan diskusi hasil rancangan tim perancang kepada mitra secara periodik untuk memperoleh desain yang optimal. Sebelum menggambar desain mesin pada aplikasi Solidworks, maka harus dilakukan menggambar sketch dengan tangan terlebih dahulu. Setelah gambar sketsa yang telah disetujui, maka selanjutnya dipilih satu model untuk dibuat model 3D di Solidworks.

\section{Pembuatan mesin:}

Pembelian bahan baku menjadi awal pembuatan mesin, selanjutnya melakukan proses fabrikasi yang dilaksanakan oleh tim pelaksana dibantu oleh tenaga ahli. Komponen dirakit sesuai dengan urutan proses perakitan hingga mesin terakit sempurna.

\section{Uji coba mesin:}

Pengujian mesin dilakukan untuk menghitung performa mesin serta melakukan pengecekan mesin apakah sudah bekerja sesuai dengan rancangan. Tahapan ini dilakukan ileh tim pelaksana dan perancangan sesuai dengan prosedur (Alqadri, 2019).

\section{Penyerahan mesin:}

Mesin yang sudah dilakukan uji coba dan memiliki performa sesuai dengan perancangan awal serta bekerja sesuai rancangan, maka alat diserahkan kepada mitra.

\section{Pelatihan penggunan mesin:}

Mesin yang telah selesai diuji dan diserahkan kepada mitra, selanjutnya mitra diberi pelatihan tantang tatacara penggunaan dan pemanfaatan mesin.

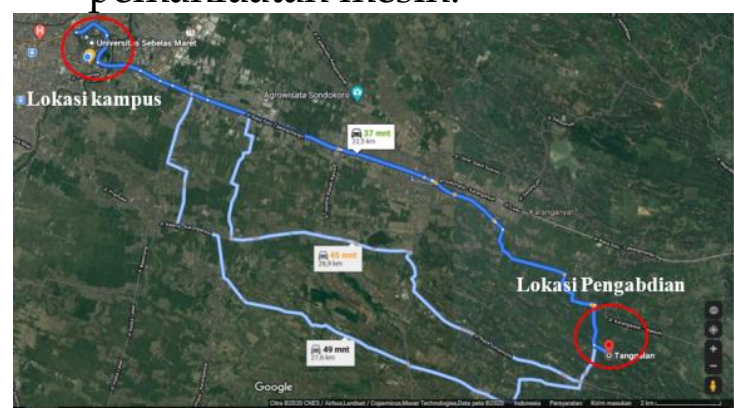

Gambar 1. Lokasi Pengabdian

\section{Perancangan Alat}

Berdasarkan permasalahan yang ada dengan kualitas pasir sungai yang berada dipasaran (Gambar 2) dan efektifitas pengayakan yang ada maka perlu dilakukan perancangan alat yang sesuai. Dalam mendesain suatu alat/mesin maka perlu memperhitungan daya yang dibutuhkan untuk mendapatkan kapasitas dari alat/mesin yang diinginkan (Arifin et al., 2019; Cahyono et al., 2019; Sateria et al., 2019).

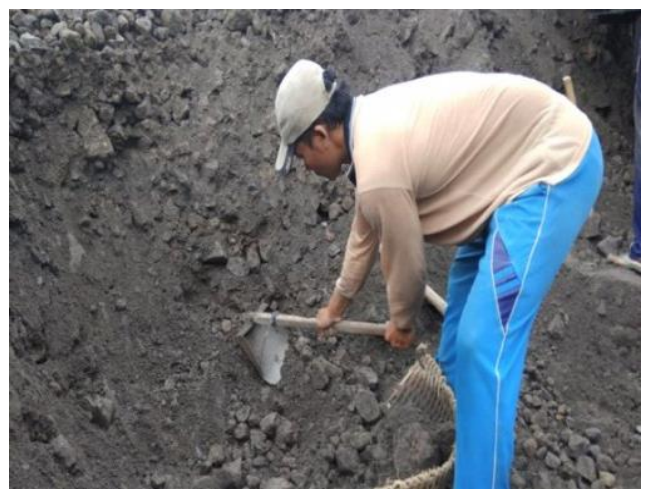




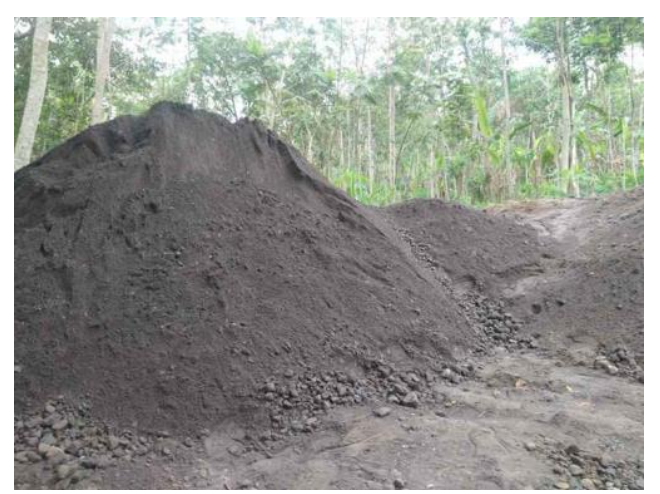

Gambar 2. Kualitas Pasir Sungai Dipasaran

Secara umum daya diartikan sebagai suatu kemampuan yang dibutuhkan untuk melakukan sebuah kerja, yang dinyatakan dalam satuan Watt ataupun hp (horse power). Penentuan besar daya yang dibutuhkan perlu memperhatikan beberapa hal yang mempengaruhinya, diantaranya adalah berat dan gaya yang bekerja pada mekanisme, serta kecepatan putar dan torsi yang terjadi. Berikut adalah rumus-rumus yang digunakan (Aprilman, 2019; Mott \& Tang, 2004):

Berdasarkan torsi dan kecepatan sudut yang bekerja, daya dirumuskan sebagai berikut.

$$
\begin{aligned}
& P=T \cdot \omega \\
& \text { Keterangan : } \\
& P=\text { Daya } \\
& \text { (Watt) } \\
& T=\text { Torsi } \\
& \text { (Nm) } \\
& \omega=\text { Kecepatan sudut } \\
& (\mathrm{rad} / \mathrm{s})
\end{aligned}
$$

Berdasarkan momen inersia dan percepatan sudut torsi dapat dicari dengan rumus sebagai berikut.

$$
T=1 . a
$$

Keterangan:

$$
\begin{array}{ll}
l=\text { momen inersia } & \left(\mathrm{kg} / \mathrm{m}^{2}\right) \\
\alpha=\text { percepatan sudut } & (\mathrm{rad} / \mathrm{s})
\end{array}
$$

Berdasarkan jenis bendanya inersia dapat dicari dengan rumus sebagai berikut.

$$
\begin{array}{ll}
I=m r^{2} & \\
\text { Keterangan } & \\
m=\text { massa total } & (\mathrm{kg}) \\
r=\text { jari }- \text { jari } & (\mathrm{m})
\end{array}
$$

Kecepatan sudut dan percepatan sudut dapat dicari sebagai berikut.

$$
\alpha=\frac{\omega}{\Delta t}
$$

Keterangan:

$$
\begin{array}{ll}
\alpha=\text { percepatan sudut } & (\mathrm{rad} / \mathrm{s}) \\
\omega=\text { kecepatan sudut } & (\mathrm{rad} / \mathrm{s})
\end{array}
$$

Pelaksanaan pengabdian ini digambarkan melalui Roadmap pengabdian seperti pada Gambar 3 dibawah ini.

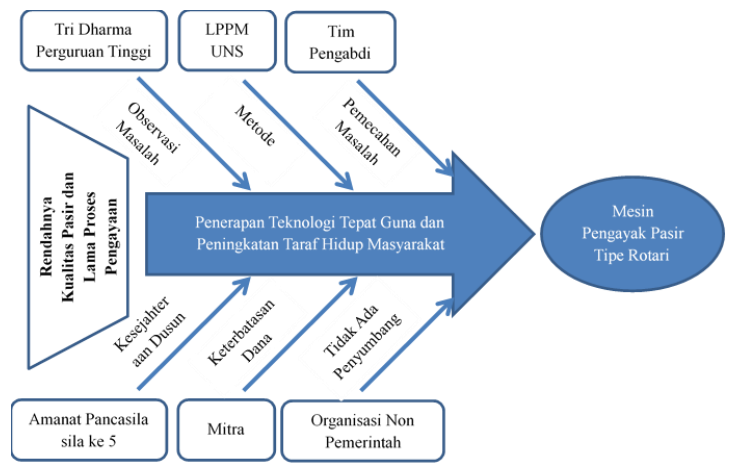

Gambar 3. Roadmap Pengabdian

\section{HASIL DAN PEMBAHASAN}

Pada mesin pengayak pasir ini menerapkan teknologi rotari dengan penggerak motor listrik 0,5 Hp dengan kecepatan $1400 \mathrm{rpm}$ (Riwu \& Mali, 2020). Daya yang ada ditransmisikan menggunakan flexible coupling dan selanjutnya diturunkan kecepatannya dengan ditambahkan speed reducer rasio 10:1. Kecepatan yang dihasilkan motor listrik masih terlalu tinggi, sehingga ditambahkan transmisi sprocket dan rantai dengan perbandingan 1:2 yang menghasilakn kecepatan akhir 70 rpm pada sprocket. Selanjutkan daya ditransmisikan melewati poros menuju tabung ayakan dengan kecepatan akhir 70 rpm. Desain 
tabung ayakan pasir dibuat berbentuk kerucut terpancung dengan tujuan untuk mengarahkan batu dan kerikil yang disaring menuju ujung lainnya.

Hasil dari desain yang telah dirancang selanjutnya di gambarkan menggunakan software Solidworks. Pembuatan desain terlebih dahulu dibuat dalam model dua dimensi dengan memastikan fungsi alat sesuai dengan kebutuhan yang telah didiskusikan sebelumnya seperti pada Gambar 4.

Untuk mempermudah pada saat berdiskusi secara detail dengan mitra pengabdian, maka gambar dituangkan dalam bentuk gambar tiga dimensi. Selain itu juga diberikan keterangan secara mendetail untuk bagian-bagian dari alatnya seperti pada Gambar 5.
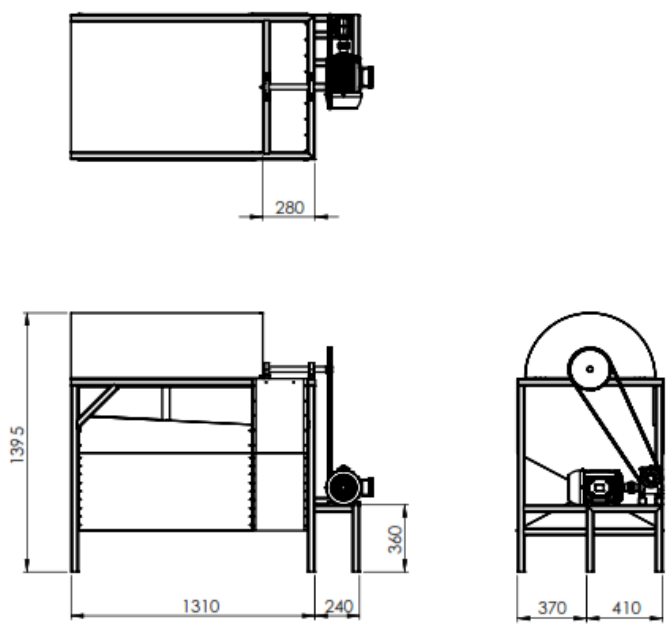

Gambar 4. Desain Mesin Pengayak Pasir Tipe Rotari

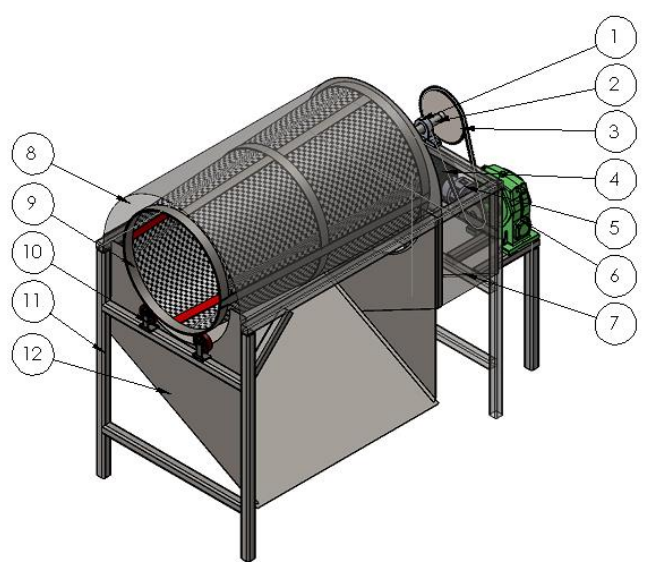

Keterangan:

1.Rumah bearing 7.Corong kerikil

2.Poros 8.Penutup mesh

3.Rantai dan sprocket 9.Ayakan pasir

4.Motor listrik 10.Roda penyangga

5.Flexible kopling 11.Rangka

6.Speed reducer 12.Corong pasir

Gambar 5. Bagian Mesin Pengayak

Proses pembuatan mesin pengayakan ini memerlukan beberapa perhitungan pada komponen utama yaitu poros dan juga system transmisi. Poros yang digunakan pada mesin ini menggunakan bahan ST 37 dengan diameter $30 \mathrm{~mm}$ dan panjang $500 \mathrm{~mm}$. Penentuan dimensi poros ini berdasarakan hasil perhitungan torsi yang bekerja akibat daya motor dan beban dari berat pengayak. Dari hasil perhitungan didapatkan nilai 23,73 $\mathrm{mm}$, sedangkan penentuan $30 \mathrm{~mm}$ berdasarakan ukuran bearing yang tersedia dipasaran dan penentuan ukuran poros yang lebih besar melihat faktor keamanannya. Pembebanan pada poros pada proses perhitungan seperti ditunjukkan pada Gambar 6 dan kemudian dihitung kesetimbangan gayanya seperti pada Gambar 7. 


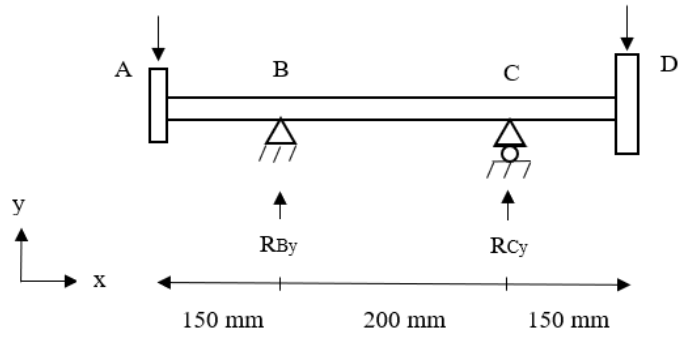

Gambar 6. Skema Pembebanan Poros

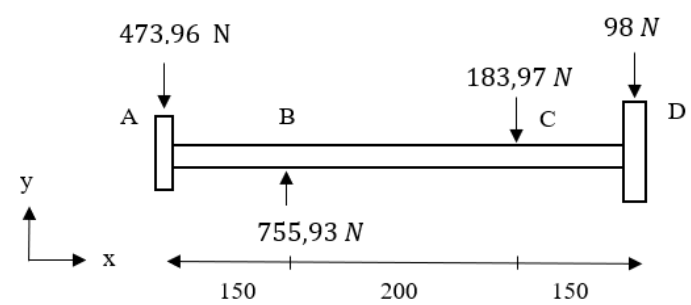

Gambar 7. Kesetimbangan Gaya

Sistem transmisi adalah sistem yang berfungsi untuk meneruskan daya dan putaran mesin menjadi daya dan putaran yang berbeda-beda untuk diteruskan ke penggerak akhir. Konversi ini mengubah kecepatan putar yang tinggi menjadi lebih rendah atau sebaliknya. Sistem transmisi yang digunakan adalah flexible kopling, pemilihan flexible kopling dikarenakan untuk mempermudah pemasangan antara motor listrik dan speed reducer sehingga mengurangi terjadinya misalignment. Sistem transmisi yang kedua adalah sproket rantai. Pemilihan transmisi sproket rantai dikarenakan untuk menghindari slip dan dapat memberikan efisiensi yang tinggi serta dengan pertimbangan kelebihan rantai yang lainnya.

Jarak yang jauh antara dua buah poros sering tidak memungkinkan transmisi langsung dengan roda gigi. Karena itu di pasanglah sebuah sabuk atau rantai pada sekeliling pulley atau sproket pada poros. Adapun macam transmisi diantaranya sistem transmisi roda gigi, sistem transmisi sabuk dan pulley, system transmisi kopling, dan sistem transmisi rantai dan sproket (chain drive).

Kopling pada poros yang digunakan dalam mesin mempunyai beberapa tujuan sebagai berikut:

1. Menyediakan koneksi pada poros yang dipasang secara terpisah seperti motor listrik dan untuk melakuhkan pemutusan pada saat perbaikan atau pergantian.

2. Mengurangi dampak misalignment dari poros.

3. Mengurangi beban kejut dari satu poros ke poros yang lain dalam transmisi.

4. Memberikan perlindungan terhadap kelebihan beban.

Persyaratan dari kopling poros yang baik adalah sebagai berikut:

1. Mudah untuk disambungkan atau dilepaskan.

2. Dapat mentrasmisikan daya maksimal dari satu poros ke poros yang lain tanpa mengalami kerugian.

3. Dapat menahan poros dalam keselarasan yang sempurna.

4. Dapat mereduksi transmisi dari beban kejut dari satu poros ke poros yang lain.

Selain poros dan system transmisi yang diperhitungkan, mesin ini memiliki keunggulan pada konstruksi ayakan yang dibuat. Ayakan ini dijepit dengan dua buah penjepit kemudian diantara penjepit itu terdapat mesh. Mesh yang digunakan menggunakan mesh ukuran 5. Selain itu, ayakan ini besifat knockdown sehingga ukuran mesh ayakan bisa diatur atau diganti sesuai dengan ukuran atau kehalusan yang 
diinginkan. Desain dari ayakan ini ditunjukkan pada Gambar 8.

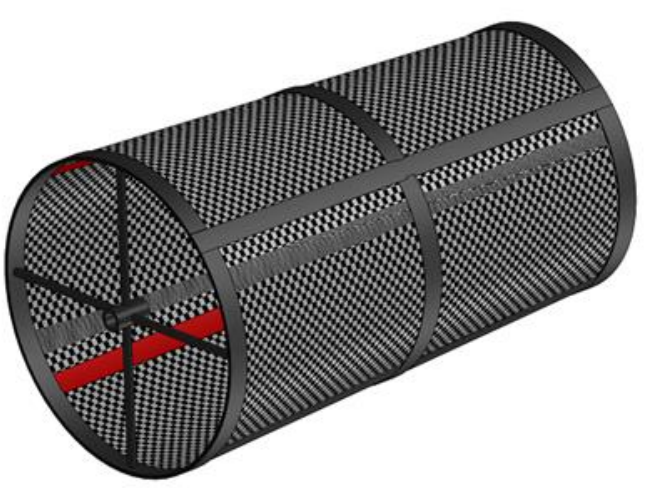

Gambar 8. Ayakan Pasir

Pembuatan kerangka mesin dibuat dengan besi hollow dengan ukuran 40x40 tebal 2,6 mm. Kerangka disambungkan dengan menggunakan sambungan las.

Penutup mesh berfungsi untuk menjaga agar debu dan pasir yang dihasilkan dari proses pengayakan tidak tersebar ke sekitar mesin. Penutup mesh terbuat dari plat besi dengan ketebalan $1 \mathrm{~mm}$. Penutup ini juga merupakan keunggulan dari produk ini sebagai antisipasi debu yang keluar akibat berputarnya mesin pengayak pasir ini.

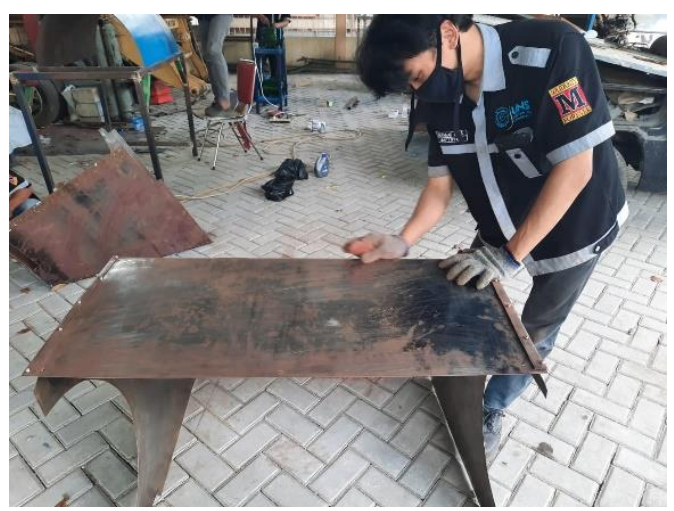

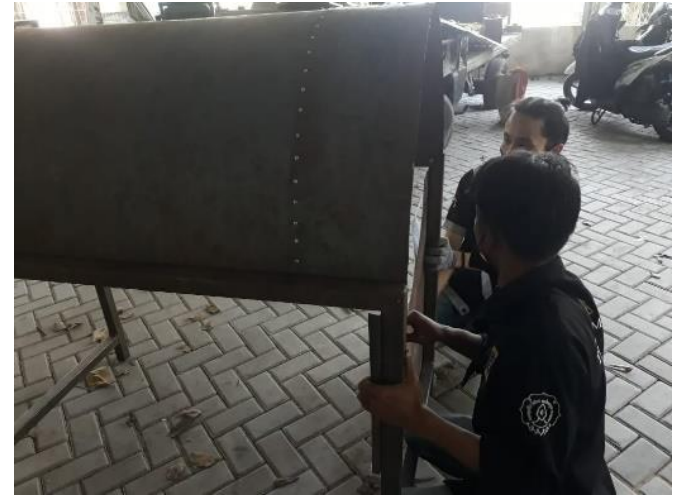

Gambar 9. Proses Pembuatan Corong Pasir dan Penutup Ayakan

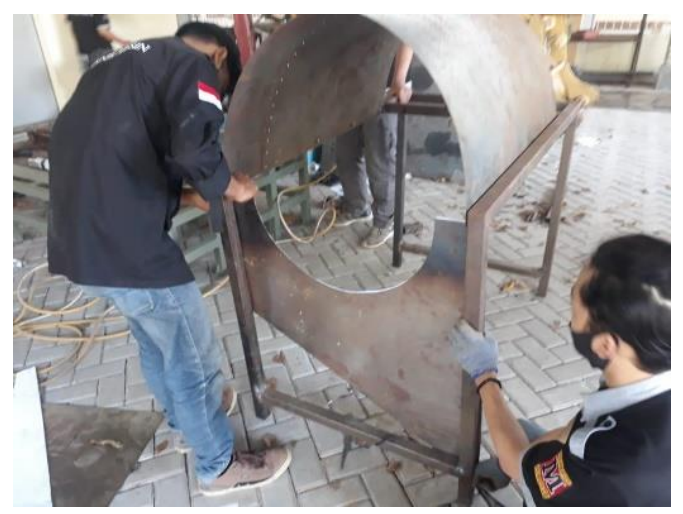

Gambar 10. Proses Pemasangan Penutup

\section{Perakitan dan Perawatan Mesin}

Perakitan adalah tahap akhir dalam proses perancangan dan pembuatan suatu mesin. Proses perakitan adalah proses menggabungkan tiap komponen dengan urutan tertentu sehingga menjadi suatu produk akhir yang siap digunakan sesuai dengan fungsinya. Komponen yang perlu disiapkan dalam perakitan mesin pengayak pasir ini adalah rangka utama, motor listrik, speed reducer, flexible kopling, rantai dan sproket, poros, bearing, ayakan, penutup mesh dan corong.

Langkah dari proses perakitan mesin pengayak pasir ini adalah sebagai berikut:

1. Memasang motor listrik dan speed reducer dengan kopling. 
2. Mengencangkan motor listrik dan speed reducer pada dudukan rangka dengan baut M8.

3. Memasang bearing dengan rumah bearing pada rangka utama dengan baut M12.

4. Memasang poros ke bearing.

5. Memasang ayakan ke poros menggunakan counter.

6. Memasang sistem transmisi rantai dan sproket pada poros dan speed reducer dengan menggunakan counter.

7. Memasang penutup mesh dengan baut M5.

8. Memasang corong pasir dengan rangka utama dengan baut M5.

9. Memasang corong kerikil dengan rangka utama dengan baut M5.

Kemudian untuk perawatan yang harus dilakuhkan secara rutin dari mesin pengayak pasir ini bisa dilakuhkan setiap saat setelah pemakian. Perawatan mesin pengayak pasir meliputi:

1. Pembersihan dilakuhkan terhadap semua komponen dari kotoran atau debu setelah pemakian. Pembersihan ini sangat penting untuk menjaga kualitas alat agar bisa digunakan secara rutin.

2. Pelumasan pada rantai harus rutin dilakuhkan agar pada saat pemakian dapat bekerja dengan baik.

3. Pelumasan pada bearing harus rutin dilakuhkan agar menjaga komponen bearing supaya tidak aus.

4. Pengecekan terhadap mesh pada ayakan untuk mengetahui kondisi mesh agar bisa digunakan dengan baik.

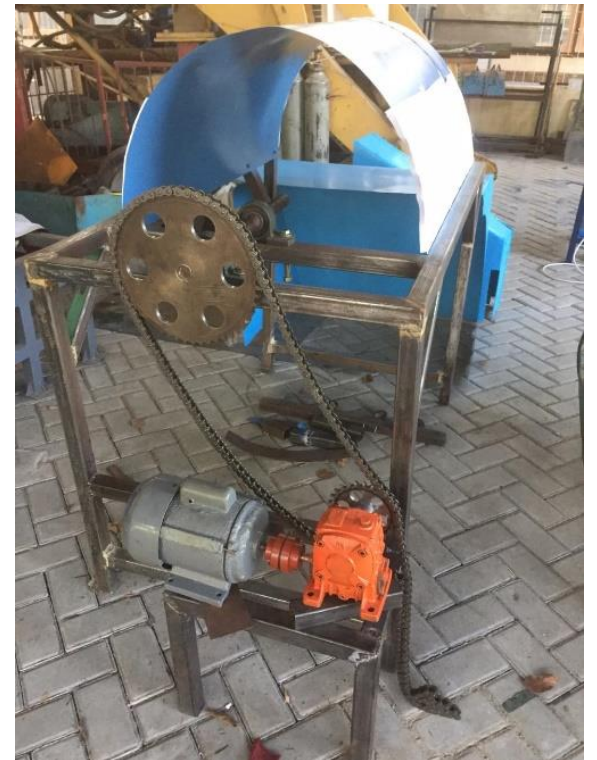

Gambar 11. Mesin Pengayak Rotary

Cara Kerja dan Pengujian Alat

Cara kerja dari mesin pengayak pasir sistem rotari ini cukup sederhana. Tenaga penggerak dihasilkan dari motor listrik dengan daya 0,5 hp dengan kecepatan 1400 rpm. Daya tersebut kemudian ditansmisikan menggunakan flexible kopling menuju ke speed reducer. Speed reducer yang digunakan dalam mesin ini adalah speed reducer dengan perbandingan 1:10. Setelah keluar dari reducer daya ditransmisikan lagi dengan transmisi sproket rantai dengan perbandingan transmisi 1:2. Setelah itu daya ditransmisikan ke poros dan menggerakan tabung ayakan dengan kecepatan akhir $70 \mathrm{rpm}$. 


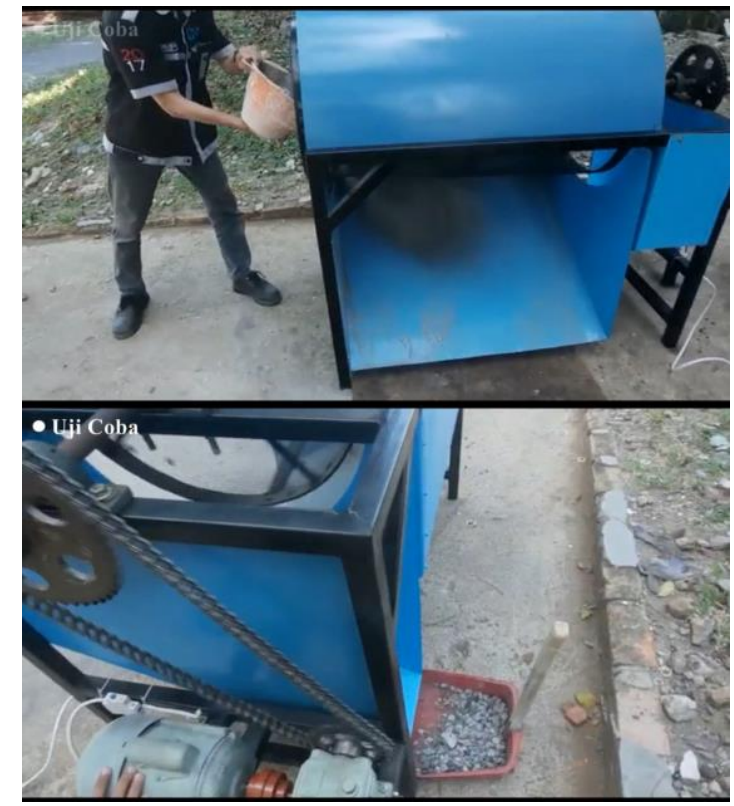

Gambar 12. Pengujian Alat

Di dalam tabung ayakan ini nantinya pasir akan dimasukkan dan diayak dengan cara memutar tabung ayakan. Setelah pasir dimasukkan maka pasir halus akan segera jatuh ke bawah dan dikeluarkan melalui lubang keluaran pasir di bawah ayakan. Sedangkan batu atau kerikil yang tertinggal di dalam ayakan akan keluar melalui lubang keluaran diujung tabung ayakan. Bentuk dari tabung ayakan didesain dengan bentuk menyerupai corong dengan diameter masukan pasir lebih kecil daripada diameter keluarnya batu atau kerikil. Dengan bentuk seperti ini maka akan mempermudah batu atau kerikil untuk keluar dari tabung ayakan. Pada Gambar 12 menunjukkan pengujian alat dengan cara melakukan pengayakan dan dihasilkan kapasitas $10 \mathrm{~m}^{3} / \mathrm{jam}$.

Setelah dilakukan pengujian maka alat diserahkan kepada mitra dan dilakukan sosialisasi penggunaan alat. Sosialisasi dan pelatihan penggunaan alat dilakukan oleh tim pengabdian serta melibatkan mahasiswa kepada perwakilan pemuda dan kepala Dusun Tanggalan. Acara dilakukan dengan memberikan arahan untuk standar operational mesin pengayak otomatis dan juga menjelaskan cara perawatannya. Sosialisasi ini dilakukan pada bulan November 2020.

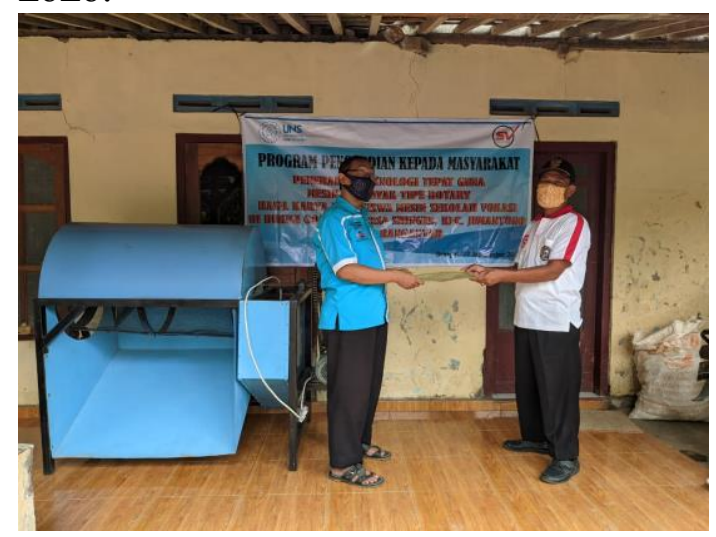

Gambar 13. Sosialisasi dan

penyerahan alat

Satu bulan setelah dilakukan penyerahan alat, dilakukan kajian ulang. Kajian dilakukan untuk melihat performa dan memastikan kegunaan alat berjalan dengan baik. Berdasarkan kajian ini didapatkan bahwa pembangunan dan peroses pengayakan yang dilakukan dengan menggunakan alat pengayak pasir menunjukkan hasil yang sangat bagus. Hasil pengayakan didapatkan peningkatan menjadi $10 \mathrm{~m}^{3} / \mathrm{jam}$ sedangkan dengan proses pengayakan manual hanya didapatkan 3-4 $\mathrm{m}^{3} / \mathrm{jam}$. Proses pengayakan yang lebih cepat $3 \mathrm{kali}$ menghasilkan pengerjaan pembangunan yang lebih cepat juga.

Pada sisi ekonomi, pengerjaan pembangunan yang lebih cepat dapat menghemat biaya dari segi honor pekerja harian. Disisilain, alat pengayak ini juga dapat 
menghasilkan pendapatan bagi Dusun Tanggalan dari hasil menyewakan mesin pada DusunDusun tetangga yang menjadi penghasilan tambahan Dusun Tanggalan

\section{KESIMPULAN}

Berdasarkan hasil dari perhitungan dan perancangan mesin pengayak pasir sistem rotary, maka dapat diambil kesimpulan sebagai berikut:

1. Daya yang ditransmisikan untuk menggerakkan ayakan bersumber dari motor listrik dengan daya 0,5 hp dan berkecepatan $1400 \mathrm{rpm}$.

2. Sistem transmisi yang digunakan adalah speed reducer untuk menurunkan kecepatan dari 1400 rpm menjadi 140 rpm dengan perbandingan 1:10. Kemudian kecepatan diturunkan lagi menjadi 70 rpm menggunakan rantai dan sproket dengan perbandingan transmisi 1:2.

3. Momen maksimal yang diterima poros adalah sebesar $71090 \mathrm{Nmm}$.

4. Poros yang digunakan pada mesin ini adalah jenis poros transmisi, dengan ukuran panjang $500 \mathrm{~mm}$, dan diameter $30 \mathrm{~mm}$, serta material yang digunakan untuk membuat poros adalah besi ST 37.

\section{DAFTAR PUSTAKA}

Aditya, C., Silviana, \& Hermawati, A. (2018). Mesin Ayakan Getar Tipe Excentric Sebagai Pengayak Butiran Marmer dan Batu Alam Pada Produksi Industri Teraso dari Limbah Batu Alam di Kabupaten Tulungagung.
PEDULI: Jurnal Ilmiah Pengabdian Pada Masyarakat, 2(2), 22-31. https://doi.org/https:/ / doi.org /10.37303/peduli.v2i2.79

Alqadri, R. (2019). Pengujian Mesin Ayakan Pasir Dengan Kapasitas Dua Kubik Pasir Perjam. Politeknik Negeri Padang.

Aprilman, D. (2019). Analisa Efisiensi Mesin Pengayak Pasir Dengan Tenaga Motor Bakar Daya 5, 5 Hp. Jurnal Teknik Mesin, 5(1), 1523.

Arifin, Z., Prasetyo, S. D., Triyono, T., Harsito, C., \& Yuniastuti, E. (2020). Rancang Bangun Mesin Pencacah Limbah Kotoran Sapi. Rekayasa Mesin, 11(2), 187-197. https://doi.org/https:/ / doi.org /10.21776/ub.jrm.2020.011.02.6

Arifin, Z., Triyono, T., Harsito, C., Prasetyo, S. D., \& Yuniastuti, E. (2019). Pengolahan limbah kotoran sapi dan onggok pati aren menjadi pupuk organik. 191-196.

Badan Standardisasi Nasional. (2002). Tata Cara Perhitungan Struktur Beton Untuk Bangunan Gedung. SNI 03-2847-2002. In SNI 03-28472002.

Cahyono, A. I., Qiram, I., \& Rubiono, G. (2019). Pengaruh Sudut Kemiringan dan Kecepatan Putaran Saringan Pada Unjuk Kerja Mesin Pengayak Pasir Tipe Rotary. V-MAC (Virtual of Mechanical Engineering Article), 4(1), 7-9.

Fattah, F. (2017). Rancang Bangun Alat Pengayak Pasir Otomatis. 01(1), 117.

Mott, R. L., \& Tang, J. (2004). Machine elements in mechanical design (Vol. 4). Pearson Prentice Hall Upper Saddle River. 
Perdana, A., \& Rusdiyantoro, R. (2013). Ancangan Pembuatan Mesin Pengayak Pasir Untuk Meningkatkan Produktivitas Kerja Operator. WAKTU, 11(2), 41-46.

Prasetyo, S. D., \& Harsito, C. (2019). Energy consumption of spray dryer machine for producing red natural powder dye and its stability Energy Consumption of Spray Dryer Machine for Producing Red Natural Powder Dye and Its Stability. 030076(April), 1-7. https:// doi.org/10.1063/1.50982 51

Riwu, T. A., \& Mali, A. W. T. S. (2020). Pengaturan Kecepatan Motor 3 Phase Pada Mesin Ayak Pasir. Universitas 17 Agustus 1945 Surabaya.

Sateria, A., Yudo, E., Zulfitriyanto, Z., Sugiyarto, S., Melati, R., Saputra, B. E., \& Naufal, I. (2019). Rancang Bangun Mesin Pengayak Pasir Untuk Meningkatkan Produktivitas Pengayakan Pasir Pada Pekerja Bangunan. Manutech: Jurnal Teknologi Manufaktur, 11(01), 8-13.

Siahaan, E. W. B. (2018). Perancangan Mesin Pengayak Pasir Dengan Kapasitas 6 , 5 m3/jam. Jurnal Darma Agung, XXVI(1), 460-475.

Tani, C. (n.d.). Perancangan Perbaikan Alat Penyaringan Beras Untuk Meningkatkan Efektivitas Di UD.

Tjahjana, D. D. D. P., Hadi, S., Wicaksono, Y. A., Kurniawati, D. M., Fahrudin, Utomo, I. S., Cahyono, S. I., \& Prasetyo, A. (2019). Study on performance improvement of the Savonius wind turbine for Urban Power System with Omni-Directional
Guide Vane (ODGV). Journal of Advanced Research in Fluid Mechanics and Thermal Sciences, 55(1), 126-135. 